\title{
Systematic review of ventricular peritoneal shunt and percutaneous endoscopic gastrostomy: a safe combination
}

\author{
Leendert H. Oterdoom, MD, PhD, ${ }^{1,4}$ D. L. Marinus Oterdoom, MD, ${ }^{2}$ Johannes C. F. Ket, ${ }^{3}$ \\ J. Marc C. van Dijk, MD, PhD, ${ }^{2}$ and Pieter Scholten, MD ${ }^{4}$ \\ 1Department of Gastroenterology and Hepatology, HAGA Ziekenhuis, The Hague; '2Department of Neurosurgery, University \\ Medical Center Groningen, Groningen; ${ }^{3}$ Medical Library, VU University Amsterdam; ${ }^{4}$ Department of Gastroenterology and \\ Hepatology, Onze Lieve Vrouwe Gasthuis (OLVG), Amsterdam, The Netherlands
}

\begin{abstract}
OBJECTIVE Various international and national gastrointestinal guidelines take different positions on whether ventriculoperitoneal shunt (VPS) insertion is a contraindication to percutaneous endoscopic gastrostomy (PEG). The objective of this meta-analysis was to try to answer the question of whether VPS insertion is a contraindication to PEG.

METHODS A systematic review of the literature was performed according to the Preferred Reporting Items for Systematic Reviews and Meta-Analyses (PRISMA) criteria. Electronic databases PubMed and Embase were searched using variations of the terms "ventriculo-peritoneal shunt" and "percutaneous (endoscopic) gastrostomy." This search resulted in 70 studies, 9 of which were relevant. These were cross-referenced, and 1 additional study was found, resulting in 10 studies in this systematic review.
\end{abstract}

RESULTS The 10 relevant studies in adult cohorts included 208 patients. All studies save one were retrospective and, in general, poor quality. Among the studies with relevant data, there were 26 ( $12.5 \%$ of 208 cases) VPS infections and 4 (4.4\% of 90 cases) VPSs that malfunctioned. In 137 patients the VPS had been placed before the PEG tube, with a VPS infection rate of $4.4 \%$. More VPS infections occurred among the 55 patients who first had a PEG and a subsequent VPS $(21.8 \%)$ and in the 16 patients who had simultaneous PEG tube and VPS placement (50\%). The heterogeneity of the studies in this analysis prohibited statistical comparisons of the timing of VPS and PEG tube placement.

CONCLUSIONS This systematic review indicated that VPS placement in combination with a PEG has a high but acceptable VPS complication rate. Therefore, VPS insertion should not be considered a contraindication to the placement of a PEG tube. Preferably, a PEG tube should be placed after the VPS. Waiting 7-10 days between VPS insertion and a PEG seems reasonable, but this could not be corroborated in this review.

https://thejns.org/doi/abs/10.3171/2016.8.JNS152701

KEY WORDS ventriculoperitoneal shunt; gastrostomy; percutaneous endoscopic gastrostomy; hydrocephalus

$\mathrm{P}$ ERCUTANEOUs endoscopic gastrostomy (PEG) is a safe and frequently performed procedure in patients who are incapable of sufficient oral intake. If more than 6 weeks of nasogastric tube feeding is expected, placement of a PEG tube can be considered..$^{13}$ Neurological disease with concomitant difficulty in or unsafe swallowing is a common indication. Some neurological diseases are accompanied by hydrocephalus, requiring drainage of cerebrospinal fluid (CSF). Ventriculoperitoneal shunting is a widely used method..$^{17}$

Some gastrointestinal guidelines consider ventriculoperitoneal shunt (VPS) insertion as a contraindication to PEG. ${ }^{23}$ Other guidelines state that VPS placement is a relative contraindication, ${ }^{9,11}$ but they only refer to pediatric cohorts $^{6,19}$ or have no references at all. Two other guidelines do not consider VPS insertion a contraindication to a PEG ${ }^{12,13}$ but they only cite a single article in support of this recommendation.? To the best of our knowledge, neurological or neurosurgical guidelines do not have a position on the combination of VPS and PEG tube placement.

Given the conflicting advice contained in the different guidelines and the sparse supporting references cited by the guidelines, we performed a systematic review to better determine whether VPS insertion should be considered a contraindication to PEG. We also posed 2 specific questions: 1) Is the order of placement (first VPS then PEG or first PEG then VPS) related to the VPS complication rate? and 2) Is there a relation between the time interval

ABBREVIATIONS CSF = cerebrospinal fluid; PEG = percutaneous endoscopic gastrostomy; VPS = ventriculoperitoneal shunt.

SUBMITTED November 20, 2015. ACCEPTED August 8, 2016.

INCLUDE WHEN CITING Published online December 2, 2016; DOI: 10.3171/2016.8.JNS152701. 
TABLE 1. Complications in adults who underwent VPS and PEG tube placement, according to the order of placement

\begin{tabular}{ccccc}
\hline Group & PEG Complication & VPS Infection & VPS Malfunctioning & Overall VPS Complications \\
\hline All adult patients ( $=208)$ & $7 / 79(8.9 \%)$ & $26 / 208(12.5 \%)$ & $4 / 90(4.4 \%)$ & $30 / 206(14.4 \%)$ \\
\hline $\begin{array}{c}\text { All adult patients, except those with } \\
\text { simultaneous placement ( }=192)\end{array}$ & $7 / 79(8.9 \%)$ & $18 / 192(9.4 \%)$ & $4 / 90(4.4 \%)$ & $22 / 192(11.4 \%)$ \\
\hline VPS then PEG ( $=137)$ & $7 / 79(8.9 \%)$ & $6 / 137(4.4 \%)$ & $4 / 90(4.4 \%)$ & $10 / 137(7.3 \%)$ \\
\hline PEG then VPS ( $=55)$ & $0 / 0$ & $12 / 55(21.8 \%)$ & $0 / 0$ & $12 / 55(21.8 \%)$ \\
\hline Simultaneous placement $(\mathrm{N}=16)$ & $\mathrm{NS}$ & $8 / 16(50 \%)$ & $\mathrm{NS}$ & $8 / 16(50 \%)$ \\
\hline
\end{tabular}

$\mathrm{N}=$ number of patients; $\mathrm{NS}=$ not specified.

Denominators reflect the number of patients from studies reporting a specific outcome.

between VPS and PEG tube placement, and the VPS complication rate.

\section{Methods}

We developed a review protocol based on the Preferred Reporting Items for Systematic Reviews and Meta-Analyses (PRISMA) statement (www.prisma-statement.org). Electronic databases PubMed and Embase were searched (L.H.O. and J.C.F.K.) for the period from database inception up to October 1,2015. The following terms, as well as synonyms and closely related words, were used as index terms or free-text words: "ventriculo-peritoneal shunt" or "VPS" and "percutaneous (endoscopic) gastrostomy" or "PEG." The full search strategies for the PubMed and Embase databases can be found in our Supplementary Tables 1 and 2. Duplicate articles were excluded.

Two reviewers (L.H.O. and P.S.) performed the literature search and selected articles. Disagreements between the reviewers were resolved by consensus. Eligibility cri- teria were that all studies report outcomes in patients who had undergone both PEG tube and VPS insertion, regardless of the order of placement. Non-English language studies were included. Congress abstracts were excluded in the systematic review but were reported to determine if they were a possible source of bias. Case reports were also excluded because of possible bias (probably no case reports of successful VPS and PEG tube placement). We also excluded studies performed in pediatric cohorts to decrease confounding since age is considered a risk factor for VPS infection in some studies. ${ }^{21}$ Our search resulted in 70 publications, 45 of which were excluded because they were not relevant, 12 because they were case reports, and 4 because the studies had been performed in children (Fig. 1). There were 9 relevant studies in adults. ${ }^{1,2,7,10,15,18,20,22,24}$ The references were cross-referenced for further original data, and we identified an additional relevant study. ${ }^{8}$ We found 2 studies that were only published in abstract form. ${ }^{3,14}$

If possible, we extracted the following information

TABLE 2. Summary of details of 10 studies of adults with VPS and PEG tube placement

\begin{tabular}{|c|c|c|c|c|c|}
\hline Authors \& Year & $\begin{array}{l}\text { Duration of } \\
\text { Study }\end{array}$ & Type of Study & $\begin{array}{c}\text { Time Btwn VPS \& PEG } \\
\text { Placement }\end{array}$ & Follow-Up & Control \\
\hline Graham et al., 1993 & 1990-1992 & Single center prospective & Minimally 1 wk, mean of 2.2 wks & Mean 8.6 mos, range 1-24 mos & None \\
\hline Grant, 1993 & 1985-1992 & Single center retrospective & NS & "Postoperative follow-up" & None \\
\hline Taylor et al., 2001 & 1995-1999 & Double center retrospective & Simultaneous & $\begin{array}{l}\text { Mean } 22.5 \text { mos, range 7-46 } \\
\text { mos }\end{array}$ & $\begin{array}{l}0 / 21 \\
\text { (VPS control) }\end{array}$ \\
\hline $\begin{array}{l}\text { Baird \& Salisidis, } \\
\quad 2004\end{array}$ & 1991-1999 & 3 centers, retrospective & 33 days & Range 3-40 mos & None \\
\hline $\begin{array}{l}\text { Schulman \& Saw- } \\
\text { yer, } 2005\end{array}$ & 1995-2004 & Single center retrospective & Mean 43.1 days & NS & None \\
\hline Nabika et al., 2006 & $1996-2002$ & Single center retrospective & $\begin{array}{l}\text { All: } 29.3 \text { days } \\
\text { VPS then PEG: } 27.2 \text { days } \\
\text { PEG then VPS: } 39.2 \text { days }\end{array}$ & $\begin{array}{l}\text { Mean } 66 \text { days, range } 14-165 \\
\text { days }\end{array}$ & $\begin{array}{l}6 / 123(4.9 \%) \\
p=0.052 \\
\text { (VPS control) }\end{array}$ \\
\hline Roeder et al., 2007 & 1990-2002 & Single center retrospective & NS & Minimally $1 \mathrm{yr}$ & $\begin{array}{l}\mathrm{N}=105 \\
\text { (PEG control) }\end{array}$ \\
\hline Cairns et al., 2009 & $2002-2007$ & Single center retrospective & $\begin{array}{l}\text { Median } 79.5 \text { days, range 1-943 } \\
\text { days }\end{array}$ & $\begin{array}{l}\text { Median } 24 \text { mos, range } 0.5-60 \\
\text { mos }\end{array}$ & None \\
\hline Kim et al., 2009 & 1999-2006 & Single center retrospective & 308.7 days, range $65-831$ days & $\begin{array}{l}\text { Mean } 6.4 \text { mos, range } 1-15 \\
\text { mos }\end{array}$ & $\begin{array}{l}\mathrm{N}=48 \\
\text { (PEG control) }\end{array}$ \\
\hline Vui et al., 2013 & $\begin{array}{l}18 \text { mos, } \\
\text { years not } \\
\text { specified }\end{array}$ & Single center retrospective & 61 days, range $1-187$ days & 140 days, range $20-570$ days & None \\
\hline
\end{tabular}


Identification

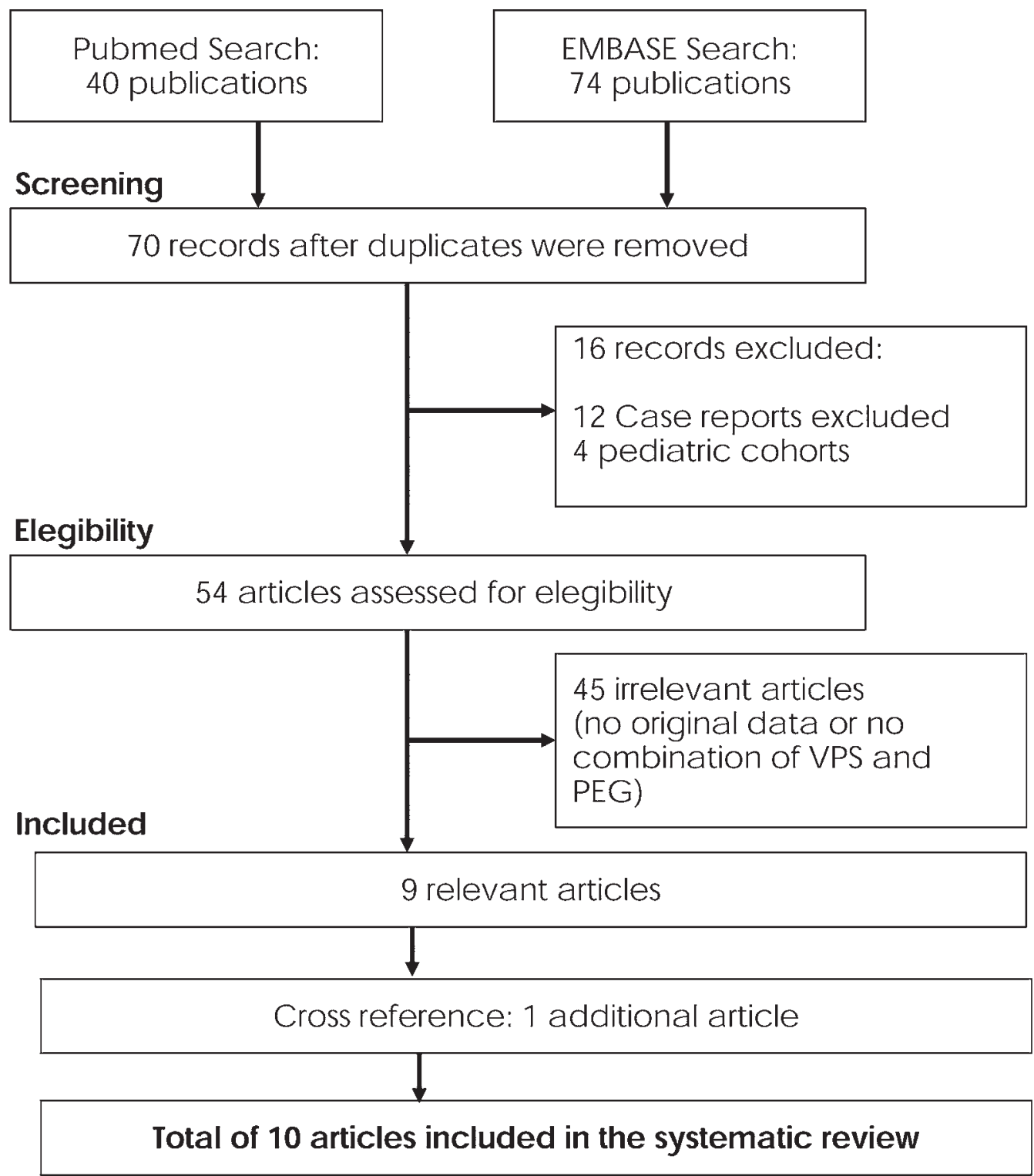

FIG. 1. Flowchart of systematic search of PubMed and Embase databases, for the period from database inception to October 1 , 2015.

from the studies: duration of study, number of patients, order of VPS and PEG tube placement, use of prophylactic antibiotics, type of PEG (pull PEG, push PEG, or surgical placement), interval between placement of VPS and PEG tube, duration of follow-up, PEG complications, VPS infection, VPS malfunction, overall VPS complications, and whether there was a control population. We contacted the corresponding authors if some of the data could not be found in the original articles $2,7,8,18,20$ and the 2 abstracts..$^{3,14}$ Two authors responded, but unfortunately they did not have additional data (J.S. Roth, personal communication, 2014; and R.G. Sawyer, personal communication, 2014).

The studies were summarized with the extracted data. Total number of patients and events (PEG adverse event, VPS infection, VPS malfunction, and overall adverse events) were added to calculate aggregate event rates.
Using Review Manager version 5.3, we made a forest plot for the 3 studies that included patients with both orders of placement (PEG tube then VPS and VPS then PEG tube) for overall VPS-related adverse events. ${ }^{2,15,18}$ Heterogeneity among these 3 studies was also tested with the Review Manager.

Data extracted from the articles were insufficient to investigate our question of whether there is a relation between the time interval between VPS and PEG tube placement, and the VPS infection or malfunction rate. In only 6 studies, comprising 79 patients and 13 VPS infections, were per-patient data reported. ${ }^{1,7,10,15,22,23}$ One of these studies included 8 VPS infections, making these results too heterogeneous to compare. Studies reporting only the average time between VPS and PEG tube placement were also insufficient to analyze the timing between VPS and 
TABLE 3. Details of placement method, complications, and prophylactic antibiotics

\begin{tabular}{|c|c|c|c|c|c|c|c|c|}
\hline $\begin{array}{l}\text { Authors } \\
\text { \& Year }\end{array}$ & $\begin{array}{c}\text { No. of } \\
\text { Patients }\end{array}$ & $\begin{array}{c}\text { Method } \\
\text { of PEG } \\
\text { Placement }\end{array}$ & Order & $\begin{array}{c}\text { PEG } \\
\text { Complication }\end{array}$ & $\begin{array}{c}\text { VPS } \\
\text { Infection }\end{array}$ & $\begin{array}{c}\text { VPS } \\
\text { Malfunction }\end{array}$ & $\begin{array}{l}\text { Overall VPS } \\
\text { Complications }\end{array}$ & $\begin{array}{c}\text { Antibiotic } \\
\text { Prophylaxis }\end{array}$ \\
\hline Graham et al., 1993 & 15 & Pull PEG & VPS then PEG & $0 / 15$ & $0 / 15$ & $1 / 15(7 \%)$ & $1 / 15(7 \%)$ & Cefazolin \\
\hline Grant, 1993 & 11 & Pull PEG & VPS then PEG & NS & $0 / 11$ & $0 / 11$ & $0 / 11$ & Cefazolin \\
\hline Taylor et al., 2001 & 16 & Pull PEG & Simultaneous & NS & $8 / 16(50 \%)$ & $0 / 16$ & $8 / 16(50 \%)$ & Antibiotic prophylaxis \\
\hline Baird \& Salisidis, 2004 & 6 & Pull PEG & VPS then PEG & $0 / 6$ & $0 / 6$ & $0 / 6$ & $0 / 6$ & Cefazolin \\
\hline $\begin{array}{l}\text { Schulman \& Sawyer, } \\
2005\end{array}$ & 39 & Push PEG & VPS then PEG & $4 / 39(10 \%)$ & $2 / 39(5 \%)$ & $2 / 39(5 \%)$ & $4 / 39(10 \%)$ & Antibiotic prophylaxis \\
\hline Nabika et al., 2006 & 23 & Pull PEG & $\begin{array}{l}11 \text { VPS then PEG } \\
12 \text { PEG then VPS }\end{array}$ & NS & $\begin{array}{l}1 / 11(9 \%) \\
3 / 12(25 \%)\end{array}$ & $3 / 23(13 \%)$ & $\begin{array}{l}1 / 11(9 \%) \\
3 / 12(25 \%)\end{array}$ & Cefazolin \\
\hline Roeder et al., 2007 & 55 & $\begin{array}{l}22 \text { surgi- } \\
\text { cally, } 33 \\
\text { pull PEG }\end{array}$ & $\begin{array}{l}25 \text { VPS then PEG } \\
30 \text { PEG then VPS }\end{array}$ & NS & $\begin{array}{l}2 / 25(8 \%) \\
5 / 30(17 \%)\end{array}$ & NS & $\begin{array}{l}2 / 25(8 \%) \\
5 / 30(17 \%)\end{array}$ & Antibiotic prophylaxis \\
\hline Cairns et al., 2009 & 24 & Pull PEG & $\begin{array}{l}11 \text { VPS then PEG } \\
13 \text { PEG then VPS }\end{array}$ & NS & $\begin{array}{l}1 / 11(9 \%) \\
4 / 13(31 \%)\end{array}$ & NS & $\begin{array}{l}1 / 11(9 \%) \\
4 / 13(31 \%)\end{array}$ & $1.5 \mathrm{~g}$ Cefuroxime \\
\hline Kim et al., 2009 & 7 & Pull PEG & VPS then PEG & $1 / 7(14 \%)$ & $0 / 7$ & $0 / 7$ & $0 / 7$ & Antibiotic prophylaxis \\
\hline Vui et al., 2013 & 12 & Pull PEG & VPS then PEG & $2 / 12(17 \%)$ & $0 / 12$ & $1 / 12(8 \%)$ & $1 / 12(8 \%)$ & Cefazolin \\
\hline
\end{tabular}

PEG tube placement. ${ }^{2,20}$ Other studies did not report any details of time between placement of a VPS and a PEG tube. ${ }^{8,18}$

\section{Results}

We found 10 eligible studies performed in adults, which included 208 patients (Table 1). Nine of the 10 studies were retrospective and most were single center. The PEG tubes were mainly endoscopically placed (89\% cases). Tubes in the remaining $11 \%$ were surgically placed. In 3 studies some patients did not receive antibiotics. Among the patients who underwent sequential rather than simultaneous VPS and PEG tube placement (192 patients), 18 (9.4\% of 192) had VPS infections, 4 (4.4\% among the 90 cases with reported data) had VPS malfunctions, 22 (11.4\% of 192 patients) had overall VPS complications (infection and malfunction), and 7 had PEG complications (8.9\% among the 79 cases with data). Details of the different studies are shown in Tables 2 and 3.

In 137 patients the VPS placement preceded the PEG tube placement, whereas in 55 patients the order of the procedures was reversed. Fewer VPS infections occurred when a VPS was placed before a PEG (6 [4.4\%] of 137 cases) as compared with the reverse order (12 [21.8\%] of 55). There were also fewer overall complications in patients with VPS placement preceding PEG tube placement (7.3\% vs $21.8 \%$ ). One study with simultaneous VPS and PEG tube placement in 16 patients described a VPS infection rate of $50 \% .^{22}$ Data for each study are shown in Tables 2 and 3. A summary of the 3 studies with both orders of placement is featured in Fig. 2. The forest plot indicates fewer VPS infections in the group that first had a VPS and then a PEG. These 3 studies were comparable and lacked heterogeneity as judged by the high $\mathrm{p}$ value for heterogeneity $(\mathrm{p}=0.88)$ and low $\mathrm{I}^{2}(0 \%)$.
Two studies had an appropriate VPS control population (that is, VPS placement without PEG). ${ }^{15,22}$ These 2 studies could not be directly compared, however, because the VPS and PEG tube had been placed simultaneously in the study by Taylor et al. ${ }^{22}$ In that study none of the 22 patients with a VPS alone (and no PEG) had a VPS infection. In the study by Nabika et al., ${ }^{15} 6$ VPS infections (5\%) were noted in 123 patients with a VPS, as compared with 4 VPS infections (17\%) in the 23 patients with a VPS and PEG tube $(\mathrm{p}=0.052)$. The higher VPS infection rate in that study was mainly attributable to the 12 patients with PEG tube placement prior to VPS placement (3 [25\%] of $12 \mathrm{vs}$ control; $\mathrm{p}=0.01$ ). In the 11 patients with a VPS prior to PEG tube placement, there was no significant difference ( 1 [9\%] of 11 vs control; $p=0.2){ }^{15}$

Two studies had PEG patients as controls (PEG without VPS). The first study did not show a higher mortality rate 1 year after PEG in the patients with a VPS and PEG tube compared with the patients with only a PEG.$^{18}$ The second study did not indicate a greater PEG complication rate in patients with or without a VPS. ${ }^{10}$

Time between VPS and PEG placement could not be systematically compared because the data were too heterogeneous. One study reported a higher VPS complication rate if the time between VPS placement and PEG was $<10$ days (3 [30\%] of 10 cases) compared with $\geq 10$ days ( 2 [14\%] of $14 ; p=0.7)$. Although this is a clinically relevant difference, it was no a statistically significant difference.

\section{Discussion}

Patients with hydrocephalus and a VPS sometimes have an indication for a PEG for adequate feeding. Guidelines provide little, and sometimes even contradictory, evidence on whether a VPS should be considered a contraindication to PEG. ${ }^{9,11-13,23}$ In our analysis of adults with hydrocepha- 


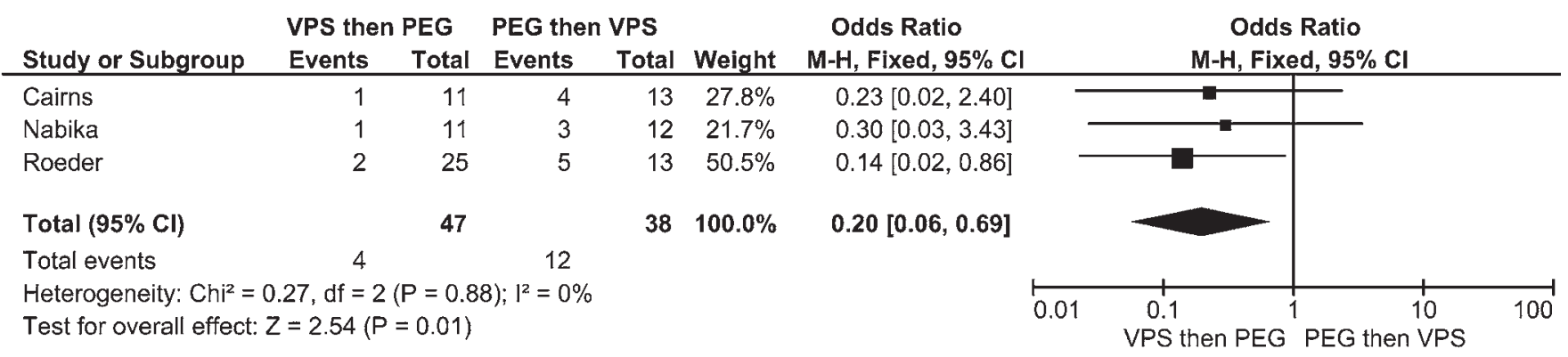

FIG. 2. Forest plot of the 3 studies including both placement orders (VPS then PEG and PEG then VPS). Data were analyzed with Review Manager version 5.3. M-H = Mantel-Haenszel.

lus who had undergone sequential, rather than simultaneous, VPS and PEG tube placement, there were $8.9 \%$ PEG complications ( 7 of the 79 cases with available data), $9.4 \%$ VPS infections (18 of 192 cases), and 4.4\% malfunctioning VPSs (4 of 90 cases). These data suggest that VPS insertion is not a contraindication to PEG. A VPS infection rate of $4.4 \%$ among 137 adults with VPS placement first and then PEG is well within the VPS infection rate of $4 \%-8 \%$ seen in most adult neurosurgical units. ${ }^{17,25}$ Judging from these data, we think that VPS insertion should not be considered a contraindication to PEG tube placement.

All VPS infections are important because of the morbidity associated with them. Mortality in patients with VPS infections was reported as high as $14 \% .{ }^{16}$ In up to $80 \%$ of shunt infections, additional surgical procedures are required. Surgical procedures can include removal with or without temporary external ventricular drainage or VPS revision. Treating VPS infections is time consuming and costly, and every additional procedure has the inherent risks of intracranial bleeding and new infections., ${ }^{46}$

The VPS infection rate is lower if the PEG tube is placed after the VPS (4.4\% vs $21.8 \%)$. Although the reviewed studies were heterogeneous, we believe that the order of placement can be directly compared because of the clear distinction in the order of placement. Only after combining the results of the 3 studies with both orders of placement was it apparent that the order of placement is important. . $^{2,15,18}$

In the studies included in this systematic review, there were very few PEG complications (8.9\% among the 79 patients from reporting studies). This rate is much lower than that reported in the general literature whose PEG complication rate is between $13 \%$ and $70 \% .^{5}$ A likely explanation for this finding is the retrospective nature of the studies included in our systematic review and the emphasis on VPS complications and not PEG complications.

Unfortunately, it was not possible to analyze the timing between VPS and PEG tube placement in relation to the VPS complication risk. One of the authors we contacted for additional data suggested waiting a minimum of 3 days but preferably 7 days (J.S. Roth, personal communication, 2014). Another author was comfortable waiting only 1 day between VPS and PEG tube placement (R.G. Sawyer, personal communication, 2014). Cairns et al. suggested waiting at least 10 days ${ }^{2}$ however, their VPS infection rate did not differ if the PEG tube was placed within or after 10 days of VPS insertion. Kim et al. advised waiting 14 days. ${ }^{10}$ Others advocated waiting at least 1 month. ${ }^{15}$ However, data from our systematic review do not suggest that the VPS complication rate is lower if you wait that long. All PEGs are elective procedures, and tube feeding is a safe alternative while waiting for a safe window for PEG tube placement. Judging from our own experience and the literature, waiting at least 7-10 days is advisable.

The main limitation of this systematic review is inherent to the data that are summarized. All but one of the studies were retrospective, and there are likely many confounders that were not corrected for. One could question whether outcomes of the 10 studies can "just" be added, as we did in Table 1. A subset of 3 studies analyzed with Review Manager gave similar results and indicated little heterogeneity. Nevertheless, this systematic review combines all known data to give the best "evidence-based" advice for clinicians considering the combination of a PEG and VPS insertion. Per-patient data could have made a comparison somewhat better, but that would not have changed the retrospective nature of the data. The retrospective character and short duration of the studies will probably give an underestimation of the complications after VPS and PEG tube placement. We did not find a publication bias per se, as all outcomes are relevant, and there were no "negative" outcomes limiting publication. In the future, large prospective studies are not expected because of the small number of patients who require both a VPS and a PEG tube.

\section{Conclusions}

Ventriculoperitoneal shunt placement should not be considered a contraindication to a PEG, though the specific combination should be discussed with patients. In 137 adults with PEG tube placement after VPS insertion, the VPS infection rate was an acceptable $4.4 \%$.

\section{References}

1. Baird R, Salasidis R: Percutaneous gastrostomy in patients with a ventriculoperitoneal shunt: case series and review. Gastrointest Endosc 59:570-574, 2004

2. Cairns A, Geraghty J, Al-Rifai A, Babbs C: Percutaneous endoscopic gastrostomy and ventriculoperitoneal shunts: a dangerous combination? Dig Endosc 21:228-231, 2009

3. Cantor M, Miskovitz PF: Percutaneous endoscopic gastrostomy following ventriculoperitoneal shunting for increased intracranial pressure: preliminary report. Gastrointest Endosc 34:202-203, 1988 (Abstract)

4. Conen A, Walti LN, Merlo A, Fluckiger U, Battegay M, 
Trampuz A: Characteristics and treatment outcome of cerebrospinal fluid shunt-associated infections in adults: a retrospective analysis over an 11-year period. Clin Infect Dis 47:73-82, 2008

5. DeLegge MH, Saltzman JR, O Lipman T, Travis AC: Gastrostomy tubes: complications and their management. UpToDate. April 15, 2015 (http://www.uptodate.com/contents/ gastrostomy-tubes-complications-and-their-management) [Accessed September 21, 2016]

6. Gassas A, Kennedy J, Green G, Connolly B, Cohen J, DagEllams U, et al: Risk of ventriculoperitoneal shunt infections due to gastrostomy feeding tube insertion in pediatric patients with brain tumors. Pediatr Neurosurg 42:95-99, 2006

7. Graham SM, Flowers JL, Scott TR, Lin F, Rigamonti D: Safety of percutaneous endoscopic gastrostomy in patients with a ventriculoperitoneal shunt. Neurosurgery 32:932934, 1993

8. Grant JP: Percutaneous endoscopic gastrostomy. Initial placement by single endoscopic technique and long-term follow-up. Ann Surg 217:168-174, 1993

9. Itkin M, DeLegge MH, Fang JC, McClave SA, Kundu S, d'Othee BJ, et al: Multidisciplinary practical guidelines for gastrointestinal access for enteral nutrition and decompression from the Society of Interventional Radiology and American Gastroenterological Association (AGA) Institute, with endorsement by Canadian Interventional Radiological Association (CIRA) and Cardiovascular and Interventional Radiological Society of Europe (CIRSE). Gastroenterology 141:742-765, 2011

10. Kim JS, Park YW, Kim HK, Cho YS, Kim SS, Youn NR, et al: Is percutaneous endoscopic gastrostomy tube placement safe in patients with ventriculoperitoneal shunts? World J Gastroenterol 15:3148-3152, 2009

11. Le Sidaner A, Bouteloup C, Cano N, Schneider S, Lachaux A, Michaud L, et al: Consensus en endoscope digestive (CED) gastrostomie et jéjunostomie percutanées endoscopiques. Paris: Société Française d'Endoscopie Digestive, 2007 (http://www.sfed.org/files/documents_sfed/files/ recommandations/GastrostomieJejunostomie.pdf) [Accessed September 21, 2016]

12. Löser C: Perkutane endoskopische Gastrostomie (PEG). Berlin: Deutsche Gesellschaft fur Gastroenterologie, Verdauungs -und Stoffwechselkrankheiten, 2014. (http:// www.dgvs.de/fileadmin/user_upload/Leitlinien/richtlinienempfehlungen/5.2.PEG.pdf) [Accessed September 21, 2016]

13. Löser C, Aschl G, Hébuterne X, Mathus-Vliegen EM, Muscaritoli M, Niv Y, et al: ESPEN guidelines on artificial enteral nutrition-percutaneous endoscopic gastrostomy (PEG). Clin Nutr 24:848-861, 2005

14. Meenaghan NC, Franco E, Park AE, Roth JS: Order of placement does not change complication rates for patients with concomitant ventriculoperitoneal shunt and percutaneous endoscopic gastrostomy. Gastroenterol 134 (Suppl 1):A-891 (Abstract \#T1755)

15. Nabika S, Oki S, Sumida M, Isobe N, Kanou Y, Watanabe Y: Analysis of risk factors for infection in coplacement of percutaneous endoscopic gastrostomy and ventriculoperitoneal shunt. Neurol Med Chir (Tokyo) 46:226-230, 2006

16. Patwardhan RV, Nanda A: Implanted ventricular shunts in the United States: the billion-dollar-a-year cost of hydrocephalus treatment. Neurosurgery 56:139-145, 2005

17. Pople IK: Hydrocephalus and shunts: what the neurologist should know. J Neurol Neurosurg Psychiatry 73 (Suppl 1):i17-i22, 2002
18. Roeder BE, Said A, Reichelderfer M, Gopal DV: Placement of gastrostomy tubes in patients with ventriculoperitoneal shunts does not result in increased incidence of shunt infection or decreased survival. Dig Dis Sci 52:518-522, 2007

19. Sane SS, Towbin A, Bergey EA, Kaye RD, Fitz CR, Albright $\mathrm{L}$, et al: Percutaneous gastrostomy tube placement in patients with ventriculoperitoneal shunts. Pediatr Radiol 28:521523, 1998

20. Schulman AS, Sawyer RG: The safety of percutaneous endoscopic gastrostomy tube placement in patients with existing ventriculoperitoneal shunts. JPEN J Parenter Enteral Nutr 29:442-444, 2005

21. Simon TD, Butler J, Whitlock KB, Browd SR, Holubkov R, Kestle JRW, et al: Risk factors for first cerebrospinal fluid shunt infection: findings from a multi-center prospective cohort study. J Pediatr 164:1462-8.e2, 2014

22. Taylor AL, Carroll TA, Jakubowski J, O'Reilly G: Percutaneous endoscopic gastrostomy in patients with ventriculoperitoneal shunts. Br J Surg 88:724-727, 2001

23. van den Berg JP, de Goeijen JC, Kruitwagen-van Reenen ET, Piepers S, van der Kooi AJ, Westermann EJA: Richtlijn Percutane Endoscopische Gastrostomie sonde (PEGsonde) plaatsing bij patiënten met Amyotrofische Laterale Sclerose (ALS). Amsterdam: ALS Centrum Nederland, 2010 (http://www.als-centrum.nl/wp-content/uploads/2013/11/ Richtlijn-PEG-bij-ALS1.pdf) [Accessed September 21, 2016]

24. Vui HC, Lim WC, Law HL, Norwani B, Charles VU: Percutaneous endoscopic gastrostomy in patients with ventriculoperitoneal shunt. Med J Malaysia 68:389-392, 2013

25. Wang KW, Chang WN, Huang CR, Tsai NW, Tsui HW, Wang $\mathrm{HC}$, et al: Post-neurosurgical nosocomial bacterial meningitis in adults: microbiology, clinical features, and outcomes. J Clin Neurosci 12:647-650, 2005

\section{Disclosures}

The authors report no conflict of interest concerning the materials or methods used in this study or the findings specified in this paper.

\section{Author Contributions}

Conception and design: LH Oterdoom, Scholten. Acquisition of data: LH Oterdoom, Ket. Analysis and interpretation of data: LH Oterdoom, DLM Oterdoom, Ket, Scholten. Drafting the article: all authors. Critically revising the article: all authors. Reviewed submitted version of manuscript: all authors. Approved the final version of the manuscript on behalf of all authors: LH Oterdoom. Statistical analysis: LH Oterdoom, Van Dijk. Administrative/ technical/material support: LH Oterdoom, DLM Oterdoom. Study supervision: Scholten.

\section{Supplemental Information \\ Online-Only Content}

Supplemental material is available with the online version of the article.

Supplementary Tables 1 and 2. https://thejns.org/doi/suppl/10. 3171/2016.8.JNS152701.

\section{Correspondence}

Leendert H. Oterdoom, Department of Gastroenterology and Hepatology, HAGA Hospital, Els Borst-Eilersplein 275, The Hague 2545 AA, The Netherlands. email: oterdoom@gmail.com. 